\title{
17
}

\section{Land Use Planning as a Collective Learning Spiral: The Case of Regenerative Landscape Policy and Practice}

\section{Richard Thackway, Valerie A. Brown, David Marsh}

\author{
and John A. Harris
}

\section{Key Points}

- Landscapes and land managers are intertwining social and biophysical systems that experience their own changes over time. Past land use decisions affect current conditions, which in turn strongly affect opportunities for future use and management.

- Landscapes are complex cultural and biophysical constructs; decisions that lead to improving, rather than degrading, social, economic and environmental ideals are more likely to be achieved by using a social learning cycle.

- Recognising the interconnected changes of landscapes and natural resource management (NRM) in a form that services the needs of both planners and land managers provides an alternative approach to developing land use policies and land use plans and evaluating their outcomes. 
- A social learning cycle that starts with ideals, describes the context, designs new ideas and puts them into action is familiar to both planning and management. An example of regenerative landscape planning, management and evaluation is presented below.

- Key indicators of landscape and management functions are proposed for use in this continual change process; indicators offer a basis for monitoring, evaluating and learning whether our cultural and biophysical resources are regenerative.

\section{Introduction: The Context of Land Use Planning in Australia}

Australia's Indigenous peoples did not own land or resources individually; they shared them and managed their lifestyles so that they could survive, even in the most difficult of circumstances (Arabena, 2015). For most of the time, despite Australia's uncertain climate, they lived with abundance (Gammage, 2011). The land itself, with its ancient, eroded soil base and extremes of weather conditions, was able to maintain productivity and its rich cultural living systems for over 40,000 years. European ideas of private land ownership and maximum resource extraction arrived with the First Fleet. Observations of the coastal landscape around Sydney in 1788 describe open forest and well-grassed parkland; fruit plantations and water retention systems occupied the fertile landscapes (Fitzhardinge, 1979).

Since European occupation, achievable land use decisions have been mainly judged against economic goals, with objectives based primarily on maximising yield (see Chapter 1). In current land use policy and practice, the status of the environmental resource base is either ignored or discounted. This presents an ethical question about responsibility for the landscape. A collective social learning process is required that links the spending of money and application of human capital with movement towards, or away from, desired social and environmental ideals. In a shifting climate and fast-changing human society, the outcomes of decisions in land use planning and farming practice need to be continually monitored and evaluated. 
Land use planning then becomes a continual learning process for farmers and policymakers, and landscape and land managers (Figure 17.1). A farming family can set personal ideals for the family, business and farm resource base. A government may establish more broadly based, but equally meaningful, ideals for a region or the nation. Without such ideals, there is nothing against which to test decisions; ideals come first. Decision-makers for landscapes at all physical scales, and from all sector interests, need both landscape and management literacy if their decisions are to be based on a sound understanding of what is happening in specific contexts. The following 'framing questions' might be used to inform collective decision-making towards the regenerative management of Australian landscapes:

1. Developing ideals (i.e. what should be)—how do we Australians want to live on our diverse landscape, recognising that the regenerating capacity of our unique landscapes provide the basis for our physical, economic and social health?

2. Describing context (i.e. what is) —what landscape functions (energy flows, living systems, water cycles, minerals and soils and management effects), coupled with management functions (biophysical measures, socio-economic frameworks, ethical principles, aesthetic patterns and sympathetic relationships), best support the ideals for this regenerative landscape?

3. Designing collective ideas (i.e. what could be)—which old and new aspects of planning and practice would best bring about the social and landscape learning that supports this regenerating landscape?

4. Doing the collective design in action (i.e. what can be)—what lessons can be drawn from landscape and management monitoring and evaluation for the next cycle of regenerative management?

\section{Collective Learning: The Practice}

Once a group or individuals have agreed on their interest in a particular regenerative landscape, these four framing questions may be implemented as a series of steps (see Figure 17.1). 


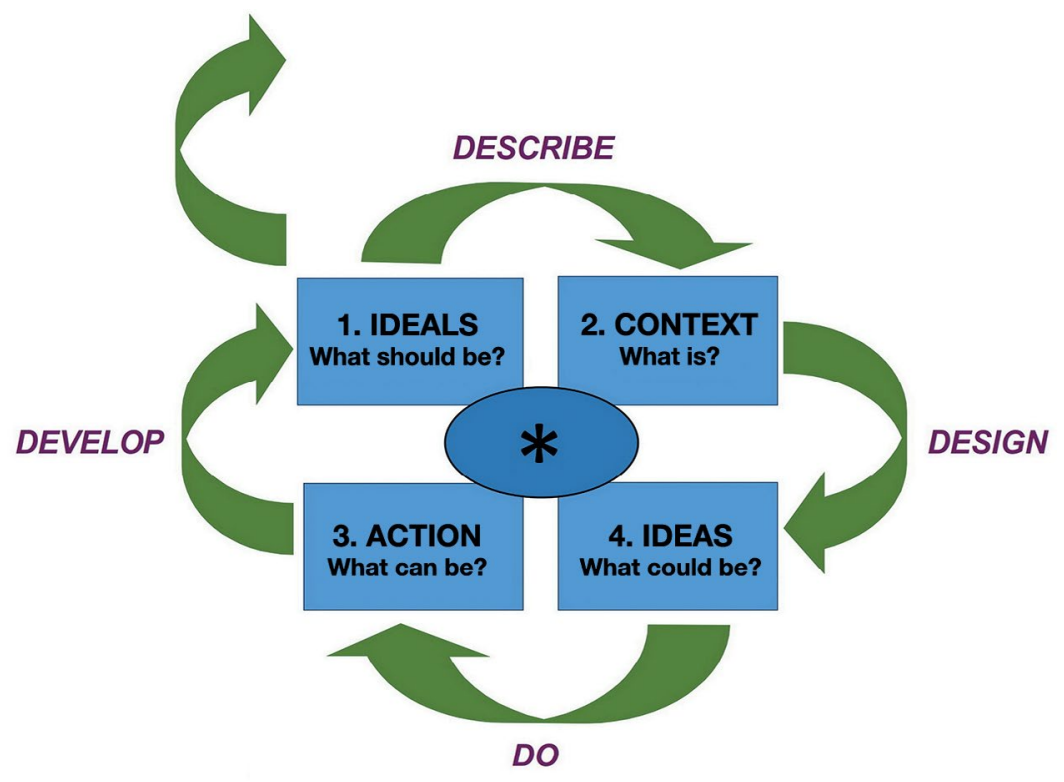

\section{* Regenerative Landscape Management}

Figure 17.1: Collective learning cycle for regenerative landscape management.

Source: Modified from Kolb (1984).

- Step 1. Respecting difference: what should be? (developing and sharing participants' ideals)

- Step 2. Ground truthing: what is? (describing interconnected landscape and management functions)

- Step 3. Brainstorming: what could be? (designing the next program drawing on creative ideas)

- Step 4. Acting: what can be? (doing the design in partnership with established practices)

Repeating the learning cycle (Figure 17.1) at regular intervals provides a continual monitoring, spiral and evaluation system (Figure 17.2). Feedback on each step serves the needs of policy development, planning, investment, mentors, community and farmers. The diagram represents the steps of the classic, adult learning cycle that is already familiar to all these interests - that is, developing ideals of what should be occurring, documenting the context of what is occurring, designing policies and programs that could be implemented to meet the ideals and implementing the ideas that can be put into practice (Brown \& Lambert, 2013). 


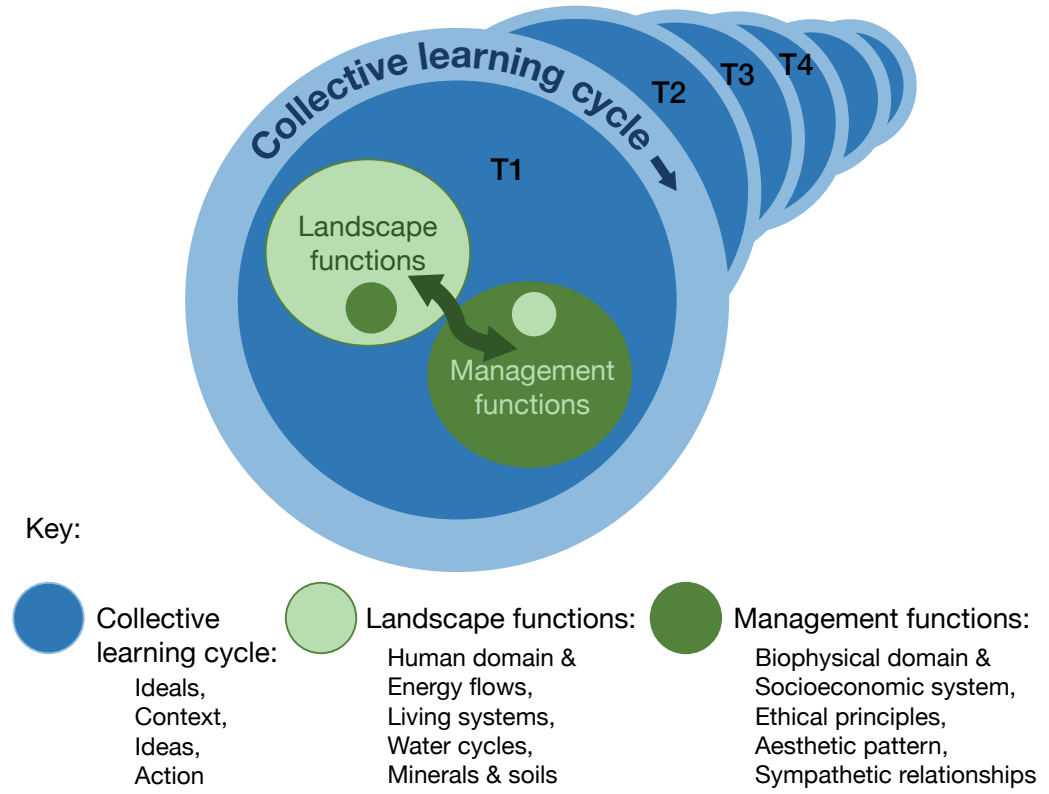

Figure 17.2: Monitoring regenerative landscape management.

Source: Authors' work.

\section{Land Use Planning as a Collective Learning Spiral}

Under current conditions for data collection, there may already exist relevant landscape and management data sets that have been collected over time. However, these collections are likely to be stored in separate compartments, frozen in time, recorded in different languages and based on incompatible units of measurement. Regenerative land use planning calls for a collaboration among the farming community, researchers, planners and innovators. This learning partnership extends to improving social health (see Chapter 11), more rigorous research (Thackway \& Lesslie, 2008) and more reliable land use planning (see Chapter 4). If land use planning is to satisfy all these needs, there must be a firm basis for collecting the full range of existing evidence for both biophysical and social landscapes. 
The collective learning spiral—developing ideals, describing the context, designing with new ideas and putting these into practice-has long been shown to apply to individual adult learning (Kolb, 1984). Over the past 30 years, the continual learning cycle (Figures 17.1 and 17.2) has been developed as a social learning cycle, evaluating and responding to transformational physical and social change (Brown, 1996; Brown \& Lambert, 2013). When the aim is to enable change rather than maintain the status quo or revert to the past, the application of the learning cycle is very different. This is the case in supporting regenerative landscapes. Existing NRM programs traditionally begin by recalling 'the facts' and describing what is presently occurring as the basis for fresh decisions (Step 2, Figure 17.1): this is a mistake. Programs for change traditionally start with brainstorming new ideas-what could ideally be occurring (i.e. what should be done), followed by the continual testing of innovative practices (Step 1, Figure 17.1). In contrast, conventional planning regimes and on-ground practice may focus on what can be done in practical terms, which amounts to a continuation of current practices. In each of these cases, unfortunately, the response to a social, environmental or economic challenge is to continue the existing way of doing things.

Ideally, a change management process should develop fresh ideals for a different future. Where the aim is maximising movement towards an ideal, instead of defending existing practice, adoption of continual learning cycles is required in the sequence of learning, as shown in Figure 17.2 (see Brown \& Lambert, 2013). Each cycle of the learning spiral starts by refreshing ideals in light of new experiences. The lessons learned through putting ideas into practice may change them in small or large ways, which results in the cycle beginning anew.

Land use planning programs that have applied this cycle include the Australian Decade of Landcare, the World Health Organization's Healthy Cities, the University of Queensland's International Water Centre, Future Earth's Transformations to Sustainability and The Australian National University's Local Sustainability Project. At the farming scale, emergent programs utilising this cycle include Holistic Management, Resource Consulting Service, Natural Sequence Farming, Prograze, Landscan and the Alliance for Regenerative Landscapes and Social Health.

Each cycle of the learning spiral for regenerative landscapes is equally relevant to leaders in the field, innovative farmers, experts, influential organisations and creative thinkers (Brown, Harris \& Russell, 2010). 
Since each of these interests has their own mode of learning and sphere of power and control, each will approach land use planning from a different perspective. Farmers and farm managers are often sole operators. Organisational interests will work within the web of their own networks. Experts operate within the frameworks and languages of their own communities of practice. Creative thinkers can come from 'left field'. Regardless of these differences, the collective learning cycle (Figure 17.1) acts as a framework for generating the ideals, context, ideas and actions of a continuous exchange process that works for all.

\section{Step 1. Collective Learning Cycle: Developing Ideals for Regenerative Landscapes}

Developing ideals is the first step in the land use planning process. The ideal of land use planning as a partnership with continually regenerating landscapes is gathering momentum throughout Australia and, indeed, the world (Mutizwa, 2015). The four authors of this paper-a regenerative farmer, an ecologist, a land use planner and a change management practitioner-described their contributions to each step of the learning cycle below.

\section{A Farmer's Ideals}

- Socio-economic: 'Living on our land in a secure family that values friendship, cooperation, humour and learning; producing a profit from livestock and plants, and [having] enough time for recreation.'

- Environmental: 'A diverse landscape with pasture year round, an efficient water cycle, soil life cycling minerals, and an increasing sunlight harvest, and management by hard work and collaboration with the local community.'

\section{An Ecologist's Ideals}

- Socio-economic: 'Personal opportunities for experiential learning, mental reflection and sympathetic curiosity, inspired by planetary interrelationships which maintain self-organising systems sustainably.'

- Environmental: 'In all species, mutually supportive communities, respect for individual differences, an ethic of justice and fairness, aesthetic patterns intrinsic to regenerative landscapes and feelings of empathy for all forms of life.' 


\section{A Planner's Ideals}

- Socio-economic: 'Land use planning built on sound data for management decisions, requiring continual monitoring of landscape and management functions towards or away from ideals.'

- Environmental: 'Land use that allows for capital increase of landscape functions: energy flows, biota, water cycles, minerals and soils and management.'

\section{A Change Manager's Ideals}

- Socio-economic: 'Collective learning between all the interests in a region working collaboratively to change existing land use planning from mechanical to regenerative agriculture and from capital growth to expanding common pool resources.'

- Environmental: 'Expanding literacy in the self-organising capacity of all environmental functions and their interrelationships with management functions.'

\section{Step 2. Collective Learning Cycle: Describing the Context of the Regenerating Landscape}

After hearing each other's ideals in Step 1, the learning moves to groundtesting those ideals in the context in which they will become operational. This seems a tall order, especially when considered alongside current practices, for which participants collect their own data, for their own purposes, in their own language. Close examination reveals that there is a single set of functions involved, and that most (if not all) of the functions are already the concern of data collections and research programs. This step in the spiral is strength-based, rather than problem-based. The question 'what is?' can be answered by sharing observations under the three main headings in Figure 17.2.

Landscape functions are shaped by five interrelated biophysical processes (Massy, 2017), namely:

- energy flows (i.e. movement of energy from the sun through a landscape)

- living systems (i.e. increasing complexity of ecological systems)

- water cycles (i.e. movement of water from the atmosphere to the landscape and back) 
- minerals and soils (i.e. movement of minerals and nutrients through living systems)

- management domain (i.e. impact of the current management system on the landscape).

Management functions are shaped by five interrelated ways of understanding the issues (Brown \& Harris, 2014):

- biophysical domain created by the landscape functions of energy, life, water and soils

- socio-economic frameworks that shape livelihoods (e.g. democracy, capitalism and productivity)

- ethical principles guiding landscape decisions (e.g. partnership, stewardship and land ownership)

- aesthetic patterns admired or rejected (e.g. pasture, crops, weeds, waterways and native forests)

- sympathetic relationships that shape personal actions (e.g. family, friendships and fauna).

\section{Example of Collective Learning Spiral Step 2}

An example of the dual management and biophysical monitoring processes are the observations recorded for the grazing system known as 'Chandler Paddock' at Severn Park in the Monaro Region, New South Wales. The manager of Severn Park described the management functions he would draw on in planning and managing a regenerative landscape thus (Massy, 2017):

- Biophysical observations: 'From 65 regenerative agriculturalists and over 2000 generations of Indigenous Australians, the conclusion is that it is only via close ecological endeavour coupled with transformational social learning that we can transform ourselves and our behaviours so as to regenerate and sustain our living and nonliving support systems for the future.'

- Socio-economic framework: shifting from the ruling mechanical, neo-liberal landscape management framework to the emerging regenerative neo-organic.

- Ethical principles: reinstating moral imperatives of collaboration with the landscape itself and among a community of regenerative farmers. 
- Aesthetic patterns: the mosaic pattern of patchwork burning, diversity of plant species in a regenerating paddock.

- Sympathetic relationships: intimacy between people and their landscapes.

The basis for this description of management functions for Chandler Paddock is the set of ideals outlined under Step 1. The human interests that determine the management regime have shared their biophysical, socio-economic, ethical, aesthetic and sympathetic ways of understanding what they seek in their management in Step 1 (see Figure 17.3). Each of these is reviewed for their status in relation to the particular place.

The basis for the description of the landscape functions in Step 2 is the vegetation, assets, states and transitions (VAST) framework ecological analysis. VAST has been developed to diagnose, account for, monitor and report on the interactions between the biophysical effects of land management on transforming landscapes over time (Thackway \& Lesslie, 2008). VAST classifies and maps vegetative land cover into 'condition classes' that reflect the energy, living systems, water status, mineral functions and management functions of a particular landscape. It follows that the categories of indicators (structure, composition and function) can be the same for all landscapes, while the actual indicators are tied to place (Thackway \& Specht, 2015).

For example, Chandler Paddock is an area of 182 hectares comprising rolling and hilly terrain, located at $-36^{\circ} 26^{\prime} 23.4600^{\prime \prime}$ S, $148^{\circ} 55^{\prime} 42.0000^{\prime \prime}$ E. After 125 years of maximum human, technical and chemical resource application, all indicators of landscape functions had fallen considerably from a reference in 1750. With the shift to regenerative farming in 2000, all indicators began a return towards the reference state (80-100 per cent).

Six phases were involved in the transformation of Chandler Paddock (Figure 17.3). Phase 1 describes the reference state. Phases 2-5 involved intensive grazing management with commensurate declines in the structure, composition and function of the site. The inclusive process, involving Steps 1-4 above, was used to initiate regenerative landscape management practices, resulting in Phase 5. A change management process, involving collective social learning, was used to initiate a new phase of regenerative landscape management (Phase 6). The observed increases in regenerative capacity, vegetation status and energy, soil water and carbon storage continue to accrue. 
Chandler Paddock, Severn Park, Monaro, NSW

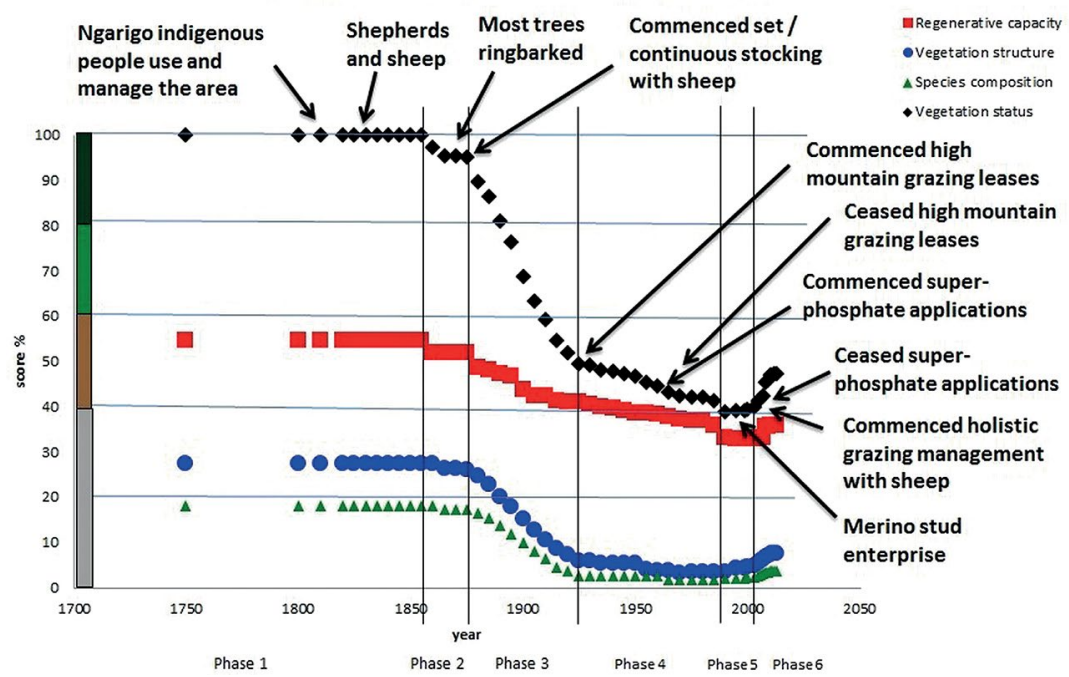

Figure 17.3. Six phases of the results of land use planning.

Source: Modified from Yapp \& Thackway (2015).

\section{Step 3. Collective Learning Cycle: Ideas for} Regenerative Landscape Management

After determining the ideals for their regenerative landscapes, and identifying the current supports and inhibitors of those ideals, the management cluster is in a good position to generate creative ideas that work over the long term.

A farmer's report:

We are turning the previous intensive farming paradigm on its head. We have seen diversity increase naturally, a key step towards achieving a sustainable social, economic and environmental resource base ideal. Previous energy intensive inputs were deemed detrimental and unnecessary. We now try to manage with contemporary sunlight energy. The effect of managing holistically on our family and the day-to-day management has been appreciating the wonder of the natural world, and knowing we can approach any type of climate variability with confidence. 
A planner's report:

Ideas that have become part of regenerative landscape management include the use of the continual learning/planning cycle [see Figure 17.2] to initiate regenerative landscape outcomes [see Figure 17.3]; an acceptance of the richness of diversity in the landscape and among landscape decision-makers; and recognition that constant change is part of the dynamic landscape and management interrelationship, and requires constant monitoring, reporting and evaluation.

\section{Step 4. Collective Learning Cycle: Putting the Ideas into Regenerative Physical and Social Practice}

Once the ideas are on the table (Step 3, Figure 17.1 and Phase 5, Figure 17.3), the decision-makers can determine which ideas are the most promising and the most practical. The current dominant landscape monitoring approach separates the biophysical and management functions, resulting in poor integration of information and suboptimal social, economic and environmental outcomes. In contrast, when decision-makers (i.e. land use policy and planning, as well as land managers) recognise that they are operating within the same regenerating landscape and that they share responsibility for working with the same set of management and landscape functions, they can represent these functions as interconnected indicators (Figure 17.4). When continually monitored for informed decision-making (Figure 17.2), these indicators improve the potential for continual social and biophysical learning.

Set of Markers for Monitoring Regenerative Landscapes

Individual reflection
Socioeconomic status as sufficiency
Ethical relationships as collaboration
Aesthetic patterns as diversity
Sympathetic feelings as community
Energy flow as vegetation cover
Living systems as ecosystem integrity
Water cycles as overall storage
Soils and minerals as resource levels
Collective reflection

Figure 17.4: Eight indicators of landscape and management functions that are applied in Figures 17.1 and 17.2.

Source: Authors' work. 
The indicators in Figure 17.4 bring together landscape and management functions for the full process of sustainable regenerative management to be monitored over time in a collaborative, appreciative process that enhances summative evaluation and learning.

The following two testimonies, which document the process of putting the ideas into regenerative physical and social practice, are informative.

A farmer's report:

We have [learned] to match our stocking rate to the carrying capacity of the landscape as it changes dynamically. This has given us confidence in knowing when to reduce stock numbers instead of hand feeding stock. Our costs have plummeted and our business is carrying a lot less debt than before. By matching stocking rate to carrying capacity we maintained ground cover during nine years of drought 2002-2010, and did not spend any money feeding stock, a huge saving. Insects, reptiles and local tree species appear in abundance. The living community has become more diverse, its natural tendency.

A planner's report:

In December 2015 there were 45 districts in New South Wales with a total of 470 regenerative landscape farmers; 109 in Western Australia, 76 in Victoria, and 7 in Tasmania involved with holistic planning (Australian Holistic Management Certified Educators). Estimations from other groups is over 700 (Marsh, David, pers. comm.). This equals the 1500 Australian farming households involved in Landcare at its peak (Brown, 1996).

The set of indicators (Figure 17.4) brings together the many ways of learning (Brown \& Harris, 2014) for each of the four learning steps (Figures 17.1 and 17.2). In practical terms, most participants will only evaluate Step 4 (Figure 17.1), whereas we propose that participants use all eight indicators to continuously improve learning in all four steps.

\section{Conclusions and Recommendations}

This chapter outlines a social learning framework for the development of monitoring and evaluation processes to transform current land management practices from a productivity-driven approach to one based on the regeneration of land and social capital. Landscapes and land managers are intertwining social and biophysical systems that 
experience their own changes over time. Past land use decisions affect current conditions, which, in turn, affect opportunities for future use and management. Landscapes are transformed by land use policies and planning that affect how the land is managed.

In complex cultural and biophysical landscapes, decisions that lead to improving, rather than degrading social, economic and environmental ideals are more likely to be achieved by using the learning cycle, in which every step is multidimensional. The magnitude of change in land management over time, and the impacts on ecosystem transformation, will determine the extent to which a landscape is regenerative. The degree to which a landscape has been changed, and an estimate of the potential for that landscape to regenerate naturally, or to be restored, involves an initial assessment and interpretation of these criteria and their associated indicators (Figure 17.3).

The degree of modification from the natural reference state will determine how likely a land manager is to be successful in improving all, or some, of the landscape's structure, composition and function. The regenerative capacity of a landscape and its component ecosystems will be determined by the degree to which an ecosystem's structure, composition and function has previously been modified, removed or replaced, as well as the type of management that is practical and feasible within cultural and biophysical constraints.

Regular monitoring and evaluation using a set of indicators of landscape and management functions, implemented as part of the continual learning cycle, are likely to improve social, economic and environmental outcomes. The development of national land use policy and planning decisions should consider the tools needed to assist decision-makers to assess regenerative landscapes and social health. That knowledge can then be used to promote and encourage the wider adoption of land management practices that, in turn, can promote improved social health.

\section{References}

Arabena, K. A. (2015). Becoming Indigenous to the universe. Melbourne, VIC: Academic Press. 
Brown V. A. (Ed.). (1996). Landcare languages: Talking to each other about living with the land. Canberra, ACT: Department of Primary Industries.

Brown V. A. \& Harris, J. A. (2014). The human capacity for transformational change: Harnessing the collective mind. London, UK: Routledge.

Brown, V. A., Harris, J. A. \& Russell, J. Y. (2010). (Eds.). Tackling wicked problems: Through the transdisciplinary imagination. London, UK: Earthscan.

Brown, V. A. \& Lambert, J. A. (2013). Collective learning for transformational change: A guide to collaborative action. London, UK: Routledge.

Fitzhardinge, L. F. (1979). A reprint of Sydney's first four years: A narrative of the expedition to Botany Bay and a complete account of the settlement of Port Jackson by Captain Watkin Tench, British Marine Officer. Sydney, NSW: Library of Australian History.

Gammage, B. (2011). The biggest estate on earth: On how Aborigines made Australia. Sydney, NSW: Allen \& Unwin.

Kolb, D. A. (1984). Experiential learning: Experience as the source of learning and development. Englewood Cliffs, NJ: Prentice Hall.

Massy, C. (2017). Call of the Reed Warbler: A new agriculture - a new earth. St Lucia: University of Queensland Press.

Mutizwa, M. (2015). Developmental work research: A tool for enabling agricultural innovation. Waginingen: Waginingen Academic Publishers (online). doi.org/10.3920/978-90-8686-819-3

Thackway, R. \& Lesslie, R. (2008). Describing and mapping humaninduced vegetation change in the Australian landscape. Environmental Management 42, 572-90. doi.org/10.1007/s00267-008-9131-5.

Thackway, R. \& Specht, A. (2015). Synthesising the effects of land use on natural and managed landscapes. Science of the Total Environment 526, 136-52. doi.org/10.1016/j.scitotenv.2015.04.070. 
Yapp, G. A. \& Thackway, R. (2015). Responding to change-criteria and indicators for managing the transformation of vegetated landscapes to maintain or restore ecosystem diversity. In J. A. Blanco (Ed.), Biodiversity in ecosystems - linking structure and function. London UK: InTech. Retrieved from www.intechopen.com/books/biodiversity-inecosystems-linking-structure-and-function/responding-to-changecriteria-and-indicators-for-managing-the-transformation-of-vegetatedlandscapes 
This text is taken from Land Use in Australia: Past, Present and Future, edited by Richard Thackway, published 2018 by ANU eView, The Australian National University, Canberra, Australia.

doi.org/10.22459/LUA.02.2018.17 